\title{
Desglycinamide-(ARG8)-vasopressin in five trials with memory-disturbed patients
}

Citation for published version (APA):

Hijman, R., Jolles, J., Verhoeven, W. M. A., Van Ree, J. M., \& Elderson, A. (1992). Desglycinamide(ARG8)-vasopressin in five trials with memory-disturbed patients. Human Psychopharmacology-Clinical and Experimental, 7, 7-23. https://doi.org/10.1002/hup.470070103

Document status and date:

Published: 01/01/1992

DOI:

10.1002/hup.470070103

Document Version:

Publisher's PDF, also known as Version of record

\section{Please check the document version of this publication:}

- A submitted manuscript is the version of the article upon submission and before peer-review. There can be important differences between the submitted version and the official published version of record.

People interested in the research are advised to contact the author for the final version of the publication, or visit the DOI to the publisher's website.

- The final author version and the galley proof are versions of the publication after peer review.

- The final published version features the final layout of the paper including the volume, issue and page numbers.

Link to publication

\footnotetext{
General rights rights.

- You may freely distribute the URL identifying the publication in the public portal. please follow below link for the End User Agreement:

www.umlib.nl/taverne-license

Take down policy

If you believe that this document breaches copyright please contact us at:

repository@maastrichtuniversity.nl

providing details and we will investigate your claim.
}

Copyright and moral rights for the publications made accessible in the public portal are retained by the authors and/or other copyright owners and it is a condition of accessing publications that users recognise and abide by the legal requirements associated with these

- Users may download and print one copy of any publication from the public portal for the purpose of private study or research.

- You may not further distribute the material or use it for any profit-making activity or commercial gain

If the publication is distributed under the terms of Article $25 \mathrm{fa}$ of the Dutch Copyright Act, indicated by the "Taverne" license above, 


\title{
Desglycinamide-( $\left.\operatorname{Arg}^{8}\right)$-Vasopressin in Five Trials with Memory-disturbed Patients
}

\author{
R. HIJMAN, J. JOLLES*†, W. M. A. VERHOEVEN $\ddagger$, J. M. VAN REE, A. ELDERSON and \\ D. DE WIED \\ Department of Psychiatry, Division of Biological Psychiatry; Department of Neurology; and Rudolf Magnus Institute
} of Pharmacology; University of Utrecht, Vondellaan 6, 3521 GD Utrecht, The Netherlands

\begin{abstract}
A series of five consecutive clinical trials were performed in which the neuropeptide desglycinamide-( $\left.\operatorname{Arg}^{8}\right)$-vasopres$\sin$ (DGAVP) was administered to human subjects suffering from cognitive and memory complaints. The patients selected for the study were carefully screened with the aid of neuropsychological assessment procedures. The trials were conducted according to a structured design in which the variables 'dose', 'route of administration', 'treatment schedule', 'diagnostic group', and 'severity of deficit' were varied from trial to trial in order to find optimal conditions for the possible expression of a peptide effect. The results indicate a statistically significant effect of DGAVP on word list learning in patients with mild brain trauma, suggesting that learning performance and memory retrieval are improved after peptide treatment in these patients. Patients with more severe brain trauma did not respond to peptide treatment. Some DGAVP effects, e.g. increased speed of memory search, were observed in patients with age-associated memory deficits.
\end{abstract}

KEY WORDS-Vasopressin, DGAVP, memory processes, cognitive processes, brain trauma, age-associated memory deficits.

\section{INTRODUCTION}

Peptides related to the pituitary hormone vasopressin (VP) have been found to influence aspects of memory processes and learning in laboratory animals (De Wied, 1969; see De Wied and Jolles, 1983; Van Ree et al., 1990 for review). This finding has led to the suggestion that VP might have clinical applications in the treatment of those neuropsychiatric diseases in which memory or other cognitive deficits are the only or major symptom.

Several clinical studies with vasopressin and related peptides have been performed. Unfortunately, it is not simple to state whether these peptides are effective, as the clinical studies differ with respect to the nature of the patients included (e.g. brain trauma, alcoholism, depression) and to the methods of medical diagnosis and neuropsychological testing. In addition, there is great variation in pharmacological parameters used, such as the dose, route and frequency of peptide adminis-

\footnotetext{
* Author to whom correspondence should be addressed. + Presently at Department of Neuropsychology and Psychobiology; University of Limburg, PO Box 616; 6200 MD Maastricht; The Netherlands.

$\$$ Presently at Psychiatric Center Venray; Stationsweg 46; 5803 AC Venray, The Netherlands.
}

tration. Some studies report positive effects of peptide administration, whereas others report that peptide administration was without effect (for a more extensive review of this matter see Jolles, 1983, 1987; Van Ree et al., 1985, 1990).

Since the first clinical trials were reported by Oliveros et al. (1978) and Legros et al. (1978), more than 60 studies have been published with a total number of patients and human volunteers exceeding 900. Most of these studies have involved volunteers (e.g. Beckwith and Sandman, 1982; Beckwith et al., 1983, 1984), alcoholics (e.g. Le Boeuf et al., 1978; Peabody et al., 1985) and patients with brain trauma (e.g. Timsit Berthier et al., 1980; Jenkins et al., 1981, 1982). In addition, trials with patients suffering from depression, schizophrenia, diabetes insipidus, Down's syndrome, heroin addiction or attention deficit disorder, among others, have been described (e.g. Weingartner et al., 1981a; Korsgaard et al., 1981; Láczi et al., 1982, 1983a,b). Several studies report beneficial effects of the peptide on processes such as attention, cognitive and memory processes, and on mood and "general activating processes' (for review see Jolles, 1983, 1987; Van Ree et al., 1985). Half of the studies performed until now (30 out of 62 studies) involved a controlled trial with patients, 20 per cent ( 13 studies) 
were not controlled. A final 30 per cent involved volunteers. It has to be emphasized that the majority of positive findings were obtained either in an open, uncontrolled clinical trial with patients (e.g. Oliveros et al., 1978) or in controlled studies with volunteers (e.g. Beckwith and Sandman, 1982; Beckwith et al., 1983, 1984; Nebes et al., 1984; Snel et al., 1987).

The majority of studies reported in the literature were heterogeneous with respect to the nature of the patient group and heterogeneous with respect to the nature of the neurocognitive disorder. That is, it has not been assessed whether the memory complaints of the subjects represented a deficit in memory functions or whether they might be a manifestation of another type of deficit (e.g. in a memory-related function such as attention or concentration). Research with VP-like peptides in human volunteers and animals has shown that the peptide might have a specific action on particular cognitive processes and not on others. For instance, Beckwith and co-workers found evidence in favour of enhanced scanning of short-term memory and enhanced selective attention in healthy young adults (Beckwith and Sandman, 1982; Beckwith et al., 1983, 1984). Research with laboratory animals by De Wied and co-workers (for review see De Wied and Jolles, 1983) have shown that vasopressin has a specific action in particular tests of learning and memory and not in others. Differential effects of vasopressin peptides have been found in rodents after lesions in particular brain structures (Van Wimersma Greidanus et al., 1976). Furthermore, it is known that there are different aspects of memory and cognition, each of which may have its own underlying neural substrate (e.g. Squire and Davis, 1981). In contrast to mild stages, advanced memory and cognitive disorders in humans are often characterized by similar complaints. This may lead to the erroneous assumption that the underlying processes are also similar.

Taken together, it is not to be expected that treatment with vasopressin peptides will be equally effective in every type of cognitive impairment. After an extensive survey of the human studies it was concluded that 'it seems that vasopressin does have behavioral effects in humans' (see Jolles, 1987, for a further discussion of this argument). Of additional importance was the fact that most studies in which the peptide was ineffective involved patients with a complex pattern of neuropsychological deficits or other symptoms suggestive of profound brain damage.
The lack of effect in patients with structural brain damage is not surprising because lesions of the relevant brain structures may well destroy the site(s) of action of the peptide. Moreover, a lack of effect of exogenously administered vasopressin peptides has also been reported for rodents with lesions of particular diencephalic areas (Van Wimersma Greidanus et al., 1976). More positive effects have been found in patients with mild (as opposed to severe) brain trauma. The same holds for the alcoholic/ Korsakoff patient and for the early versus late stages in senile dementia of the Alzheimer type. Almost all studies with volunteers have reported a positive effect of treatment (see Jolles, 1987). We therefore hypothesized that (1) the subjects of choice for vasopressin peptides would be patients with cognitive dysfunctions resulting from brain trauma, depression, senescent forgetfulness or early stages in dementia; and (2) patients should be characterized neuropsychologically to assess specific influences on different aspects of memory. In addition, the use of more specific and more sensitive methods of treatment evaluation should make it more probable that treatment effects are detected. Based on the findings with volunteers, information processing tasks should be useful in this respect (e.g. Nebes et al., 1984; Beckwith et al., 1983, 1984). The nature and amount of the pharmacologically active principle are also important. This is because the amount of vasopressin that can be used in humans is limited because of peripheral effects. Desglycinamide-( $\left.\mathrm{Arg}^{8}\right)$-vasopressin (DGAVP) is therefore favoured above desamino-D-argininevasopressin (DDAVP) and especially above $\left(\mathrm{Lys}^{8}{ }^{8}\right.$ vasopressin (LVP) because DGAVP has fewer peripheral effects than DDAVP (water retention) and LVP (blood pressure and water retention; see De Wied and Jolles, 1983 for review).

The present paper describes a series of five consecutive clinical trials in which the effect of DGAVP was tested against placebo. The patients used for the study were carefully selected by neuropsychological assessment procedures. It was deemed important to make the patient groups more homogeneous with respect to their cognitive dysfunctions and-if possible-with respect to aetiology. Therefore trials 1 through 3 were to consist only of memorydisturbed patients: that is, only those patients could be included who suffered from memory deficits which were objectively assessed by neuropsychological tests without clear-cut dysfunctions in other cognitive domains. Trials 4 and 5 were-in addition to this-homogeneous with respect to aetiology, 
respectively brain trauma and age-related memory dysfunctions. The variables 'dose', 'route of administration', 'treatment schedule', 'diagnostic group' and 'severity of deficits' were varied from trial to trial in order to find optimal conditions for the expression of a peptide effect.

\section{TRIAL}

In the first trial, the effects of DGAVP treatment were studied in patients with mild to moderate cognitive deficits. There were several important premises for the planning of this trial. Firstly, the group had to consist only of patients with memory deficits as only or major symptom, and the patients should also be in the 'mild' or 'mild to moderate' category and not 'severe'. It was therefore decided to select outpatients irrespective of the aetiology or pathogenesis of their cognitive disturbances, provided that their cognitive deficits were determined objectively and that no other pathology was present. Secondly, concerning the treatment schedule, fairly short treatment periods, i.e. acute, subacute or subchronic treatment (some weeks), had been used in earlier studies with vasopressin. As the results of several studies suggest that longer treatment periods might give better results (e.g. Timsit Berthier et al., 1980), a duration of 4 weeks was selected for the present study. Thirdly, earlier research has traditionally used intranasal administration of the peptide, although this route usually has the disadvantage that the drug quantity given cannot be controlled properly, and administration is difficult in case of rhinitis. Vasopressin peptides have been found to be effective after oral administration in patients. For instance, Fraenkel et al., 1983 and Van Beek-Verbeek et al., 1983, using sublingual administration, reported favourable effects of the substance in heroin addicts. Oral administration was therefore selected for the present study.

\section{Materials and methods}

Subjects. Fourteen outpatients participated in this trial. All subjects suffered from the late after-effect of a neurological disease and had memory complaints as their only, or major, remaining symptom. Table 1 shows the demographic and clinical data of the 13 males and one female. They had a mean age of $35 \cdot 2$ years, with a range of $18-70$ years. The group was heterogeneous as to the aetiology of the memory disorders: mild brain trauma $(n=3)$, moderate brain trauma $(n=6)$, demential syndrome
Alzheimer type $(n=2)$, learning disabilities $(n=1)$, brain surgery $(n=1)$ and brain anoxia $(n=1)$. A patient was classified as having 'moderate trauma' when one (or more) of the following criteria was/ were met: soft neurological signs found on neurological examination, detectable CT-scan abnormalities; coma duration of more than 60 minutes; posttraumatic amnesia of more than 48 hours. All other trauma patients were classified as light brain trauma. The study was approved by the Medical Ethical Committee (MEC) of the Academic Hospital of the State University Utrecht, where the study was conducted, and all subjects gave their informed consent.

Medical examination. All patients were subjected to a routine medical investigation consisting of neurological examination, evaluation of liver functions, renal functions, haematology and-if indicated-electrocardiogram. Furthermore, a neuropsychological investigation, $\mathrm{EEG}$ and $\mathrm{CT}$ scan were part of the examination screening for inclusion and exclusion criteria. Relevant inclusion criteria were the following: (a) subjective complaints about memory-related functions; (b) deficits which were determined objectively by a neuropsychological investigation; (c) the complaints or deficits had been present for at least 1 year, to ascertain that the disorder had stabilized (brain trauma) or was progressive for at least a period of 6 months (early stages of dementia). Relevant exclusion criteria were the following: (a) severe brain pathology as detected by EEG (e.g. irritative activity) and CT scan (small hypodense areas as an after-effect of brain trauma were accepted); (b) presence of neurological disorders characterized by non-cognitive symptoms or by aphasia, agnosia or apraxia; (c) affective disorders; (d) presence of cardiac insufficiency or diastolic blood pressure over $110 \mathrm{~mm} \mathrm{Hg}$; (e) liver or kidney disease; (f) severe psychiatric illness such as depression or psychosis; $(\mathrm{g})$ use of medication which can affect mental functions.

Neuropsychological investigation. The main inclusion criterion for participation in the study was the presence of memory disturbances without clearcut dysfunctions in other cognitive domains. Patients had to be characterized by one or more of the following dysfunctions: deficits in memory retrieval or memory consolidation or deficits in the speed or efficiency of memory search or deficits in the use of memory strategies. This criterion was evaluated by means of an extensive neuropsycholo- 
Table 1. Characteristics of patients and trials

\begin{tabular}{|c|c|c|c|c|c|}
\hline \multirow[t]{2}{*}{ Characteristic } & \multicolumn{5}{|l|}{ Trial } \\
\hline & 1. & 2 & 3 & 4 & 5 \\
\hline $\begin{array}{l}n \\
\text { Sex (male/female) } \\
\text { Mean age } \pm \mathrm{SD} \\
\text { Age range } \\
\text { Group composition }\end{array}$ & $\begin{array}{l}14 \\
13 \mathrm{~m}, 1 \mathrm{f} \\
35,2 \pm 19,3 \\
18-70 \\
\text { heterogene- } \\
\quad \text { ous }\end{array}$ & $\begin{array}{l}14 \\
12 \mathrm{~m}, 2 \mathrm{f} \\
39,1 \pm 13,6 \\
21-61 \\
\text { heterogene- } \\
\quad \text { ous }\end{array}$ & $\begin{array}{l}14 \\
10 \mathrm{~m}, 4 \mathrm{f} \\
41,1 \pm 17,6 \\
19-74 \\
\text { semiheterogene- } \\
\quad \text { ous }\end{array}$ & $\begin{array}{l}14 \\
10 \mathrm{~m}, 4 \mathrm{f} \\
25,1 \pm 7,8 \\
16-44 \\
\text { homogene- } \\
\quad \text { ous }\end{array}$ & $\begin{array}{l}12 \\
11 \mathrm{~m}, 1 \mathrm{f} \\
57,1 \pm 6,5 \\
48-68 \\
\text { homogeneous }\end{array}$ \\
\hline $\begin{array}{l}\text { Diagnosis } \\
\text { Mild brain trauma } \\
\text { Moderate brain trauma } \\
\text { Senescent forgetfulness } \\
\text { Dementia } \\
\text { Other diagnoses } \\
\text { Objectifyable brain dysfunction } \\
\text { Objectifyable memory deficit }\end{array}$ & $\begin{array}{l}n=3 \\
n=6 \\
n=2 \\
n=3 \\
n=12 \\
n=14\end{array}$ & $\begin{array}{l}n=2 \\
n=6 \\
n=4 \\
n=2 \\
n=13 \\
n=14\end{array}$ & $\begin{array}{l}n=3 \\
n=3 \\
n=5 \\
n=3 \\
n=7 \\
n=14\end{array}$ & $\begin{array}{l}\text { brain trauma } \\
n=12 \\
n=2\end{array}$ & $\begin{array}{l}n=10 \\
n=2\end{array}$ \\
\hline $\begin{array}{l}\text { Treatment } \\
\text { Design } \\
\text { Washout } \\
\text { Route of administration } \\
\text { Daily dose of DGAVP(mg) }\end{array}$ & $\begin{array}{l}\text { crossover } \\
\text { no } \\
\text { oral } \\
0.1\end{array}$ & $\begin{array}{l}\text { crossover } \\
\text { no } \\
\text { oral } \\
1.0\end{array}$ & $\begin{array}{l}\text { crossover } \\
\text { yes } \\
\text { intranasal } \\
1.0\end{array}$ & $\begin{array}{l}\text { crossover } \\
\text { yes } \\
\text { intranasal } \\
1.0\end{array}$ & $\begin{array}{l}\text { crossover } \\
\text { yes } \\
\text { intranasal } \\
1.0\end{array}$ \\
\hline
\end{tabular}

$n=$ number of patients.

gical examination. To that purpose a combination of methods derived from behavioural neurology, psychometric tests and information processing tasks were used. This approach allows for qualitative analysis of the total range of motor and cognitive functions and quantitative measurement of the deficits. The combination of these three approaches is more sensitive than the use of clinical memory tests, such as the Wechsler Memory Scale, Benton Tests, and Word Learning Tasks (Russell, 1981; Jolles, 1985). The tests and tasks used in our clinic to assess various aspects of cognitive/memory processes are: (a) Luria-Christensen Neuropsychological Test battery (Christensen, 1975); (b) modified version of Rey Auditory Verbal Learning Test (AVLT, see Brand and Jolles, 1985); (c) Utrecht Memory Comparison Task (Brand and Jolles, 1987); (d) Stroop Colour Word Interference Test (Lezak, 1983); (e) Utrecht Trailmaking Test (Vink and Jolles, 1985); (f) Symbol Digit Modalities Test (Smith, in Lezak, 1983). The use of this neuropsychological paradigm approach has been described more fully elsewhere (Jolles, 1985; see also Lezak, 1983). The neuropsychological investigation revealed disturbances in memory processes in all patients, as assessed by a comparison with test data of control subjects. The 14 subjects showed deficits in memory retrieval; five patients also showed dis- turbances in the consolidation of information into long-term memory. Some patients were-in addition-characterized by a disturbance in the speed of information processing and organization in memory.

Experimental design and procedure. The study was performed according to a crossover design. Treatments were administered according to a doubleblind routine. Subjects were allocated randomly to one of two groups $(n=7)$ which received either placebo treatment or drug treatment for a period of 4 weeks. There was no washout period; thus, the second treatment period immediately followed the first treatment period; placebo-treated patients received drug and vice-versa. There was a pre-test 2 weeks before the start of treatment and all subjects received placebo in these 2 weeks. Each group received DGAVP $(0.1 \mathrm{mg}$ dissolved in water $)$ or placebo once a day $(8 \mathrm{a} . \mathrm{m}$.$) . T_{1 / 2}$ of the drug is 36 minutes both after oral and after intranasal application (Westenberg, Hijman, Láczi, Van Ree and Wiegant, unpublished data). The drug was donated by Organon International bv, Oss, The Netherlands. Compliance was 'estimated' by calculating the amount taken, as determined from the amount of fluid left in the flask after each 2-week treatment period. All subjects appeared to have taken the 
necessary amount. There was a testing session every 2 weeks, which coincided with the moment that the outpatients visited the clinic to receive their medication. All subjects were tested within 7 hours after taking their medication.

Tasks used for treatment evaluation. Two tasks were used which measure different aspects of cognitive functioning. Task 1 was a Dutch version of the Rey Auditory Verbal Learning Task (Rey, 1964; Deelman et al., 1980; Brand and Jolles, 1985). Seven versions of this test have been developed and shown to be parallel (Jolles, unpublished data). These versions were used for the present study. The learning list consisted of 15 meaningful monosyllabic words which were presented in five trials. These words have a frequency of 20-400 per million, and refer to concrete objects, such as dog, moon and bread (see Brand and Jolles, 1985 for further description). Each trial ended with a free recall of the words. After a period of 20 minutes following the fifth trial, the subject was requested to recall as many words as possible (delayed recall). Immediately following this delayed recall, a recognition trial was presented consisting of the 15 words from the original learning list and 15 new but similar words drawn from the same population, presented in a random order. A tape-recorder was used for auditory presentation of the words; both the duration of each stimulus and the interstimulus interval was 1 second. Eleven variables can be derived from the test: correct number of words per trial 1, 2, 3, 4 and 5; total number of correct words on delayed recognition; total number of false positive words; total number of double words; total number of false negative words. As main variables we used (a) the total number of correct words in the five trials, (b) the total number of correct words on delayed recall, (c) the total number of correct words on delayed recognition. Task 2 was a paperand-pencil version of a memory scanning task (P\&P MST). This MST was developed by Jolles and Gaillard, and has been described in detail elsewhere (Brand and Jolles, 1987; Houx et al., 1991b). This P\&P MST resembles Sternberg's (1975) memory scanning task in a number of aspects, and has the advantage that it is easier to administer to patients and to aged subjects who suffer from cognitive dysfunctions. In addition, the test does not require extensive learning sessions and has a short duration. Finally, the test appears to have superior test-retest reliability in use with patients, when compared to an orthodox Sternberg test which is presented via a computer screen (see also Houx et al., 1991a,b). The P\&P MST consisted of two subtasks. The first subtask, which is referred to as the 'digits subtask', had three parts in which a set of one, two and four digits respectively, had to be memorized. The patient was asked to search for these digits on a test form consisting of 144 characters typed in a $12 \times 12$ matrix, four spaces apart from each other. The subject had to mark the targets with a pencil. One-sixth of these characters consisted of items from the memory set, the rest were capital letters. A practice part with the symbol '\%' as the memory set was given twice before part one (set size 1). The second subtask (the 'letters' subtask) had four parts (memory set sizes 1, 2, 3 and 4) in which items from the memory set and the 'distractor' items consisted of letters. Seven parallel versions of the task have been developed which show high inter-test reliability. The time needed to complete individual test forms was taken as a measure of particular aspects of information processing. Several parameters can be derived from the various variables, according to the additive factor method (Sternberg, 1975). This method states that several stages of information processing can be differentiated from each other. The two stages of relevance to our study are a memory comparison stage (speed of scanning and memory search) and the stage of motor organization and response execution (speed of information processing; see Nebes et al., 1984; Brand and Jolles, 1987, for further discussion). The variables chosen as parameters for treatment evaluation were the time used to complete the pretest (\%), the test with one digit, the test with one letter, and the test with four letters. From the data of the letter subtask, a slope and intercept were calculated for each individual at each testing. The total number of false negatives in the two subtasks was also analysed. As main variables we used (a) the test with one digit, as a measure of speed of information processing; (b) the test with four letters, as a measure of speed of memory search; (c) the intercept of the letter subtask, as a measure of speed of information processing and (d) the slope of the letter subtask, as a measure of memory search.

Data analyses. In order to test the hypothesis that performance in the cognitive tests was improved significantly by peptide treatment compared to placebo treatment, each variable was subjected to a three-way multiple analysis of variance (MANOVA, SPSS) with treatment (T; peptide and 
placebo), period ( $\mathrm{P}$; period 1 and period 2) and sequence $(S$; placebo-peptide and peptideplacebo) as factors. A probability of $p \leqslant 0.05$ indicated a significant effect.

\section{Results}

The analysis concerning the possible carry-over effect ( $t$-test) indicated that, for the seven main variables, no differences were present between the two sequence groups. Thus a crossover analysis was permitted. The data of the main variables are presented in Table 2. A difference between peptide and placebo treatment could lead to a significant treatment $\times$ period $(\mathrm{T} \times \mathrm{P})$ interaction (peptide effect in both sequence groups), a treatment $\times$ period $\times$ sequence $(\mathrm{T} \times \mathrm{P} \times \mathrm{S})$ interaction (peptide effect in one of the two sequence groups) or a treatment $\times$ period $\times$ sequence $(T \times P \times S)$ interaction (peptide effect in one of the two treatment groups) in the MANOVA analysis. Concerning the main variables, no significant $\mathrm{T} \times \mathrm{P}$ interaction was observed. Only the four-letter test and the slope of the memory comparison task showed a significant $\mathrm{T} \times \mathrm{P} \times \mathrm{S}$ interaction $(F=21.7, p<0.01$ and $7.6, p<0.01$ respectively), but this was due to a low score in both sequence groups in the middle of the first treatment period. The other 13 variables did not show a significant $\mathrm{T} \times \mathrm{P}$ interaction. Thus, in general, statistically significant peptide effects were not found in this trial.

\section{Discussion}

There are several factors that might explain the lack of a statistically significant peptide effect. Apart from the ultimate possibility that the peptide has no effect, there are several alternatives which must be considered. (a) The oral dose of the drug was too low. It is of interest, however, that five out of the 14 patients reported felt better; in four out of five subjects this was in the period when they received treatment with DGAVP. (b) The route of administration was not adequate. (c) The group of patients was too heterogeneous. Interestingly, the four patients who reported a beneficial effect in the peptide period were all patients with brain trauma, indicating a possible specific peptide effect in this diagnostic group. (There was one patient who reported an improvement in the placebo period; this was the patient who had undergone brain surgery.) It was decided to perform a second trial with a ten-fold higher dose of the pep- tide. Other changes were planned for future trials if trial 2 did not give more clear-cut treatment effects.

\section{TRIAL 2}

In order to allow proper evaluation of the question whether the dose level was an important factor in the lack of a statistically significant effect in trial 1 , the dose of DGAVP was increased to $1.0 \mathrm{mg}$ daily in this trial, which was identical to trial 1 in other aspects.

\section{Materials and methods}

Subjects. Fourteen patients participated in this trial; all reported complaints about memory, concentration and slowness in rate of thinking. Table 1 shows the demographic and clinical data of the 12 male and two female patients. The mean age was $39 \cdot 1$ years, with a range of $21-61$ years. This group was heterogeneous as to aetiology of the memory disorders: mild brain trauma $(n=2)$; moderate brain trauma $(n=6)$; age-related memory impairment (senescent forgetfulness, see also Crook et al., $1986 ; n=4)$; brain surgery $(n=1)$; thinking disorder after recurrent psychoses $(n=1)$. All patients met with the inclusion and exclusion criteria described in trial 1. The medical examination and neuropsychological investigation were as described in trial 1 . The trial was approved by the Medical Ethical Committee. All patients were characterized by memory deficits without clear-cut disturbances in another cognitive domain. With respect to the nature of the memory dysfunction, 11 patients showed retrieval disturbances; one patient showed disturbances in consolidation of information into long-term memory. Speed of information processing into memory was disturbed in ten patients.

Experimental design and procedure. See trial 1; the daily dose of DGAVP was $1.0 \mathrm{mg}$.

Tasks and data analysis. See trial 1.

\section{Results}

The data of one patient were not complete; therefore the data of 13 patients were statistically analysed. The analyses concerning a possible carryover effect ( $t$-test) indicated a statistically significant effect $(t=3 \cdot 1, p<0.05)$ for one of the seven 
Table 2. Effect of DGAVP on the main neuropsychological variables of the five trials

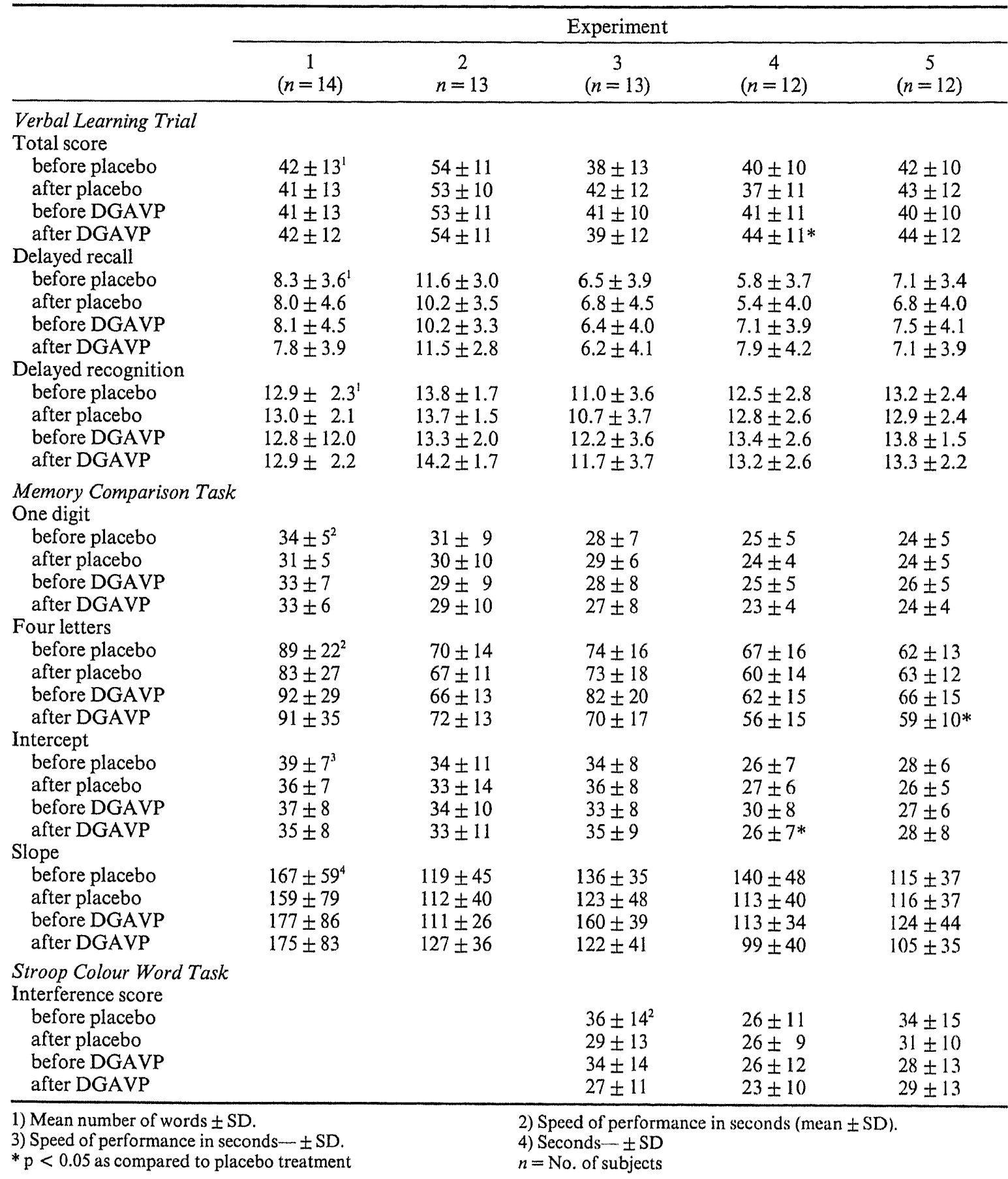

main variables. This variable, the total score of the verbal learning task, showed an increase in the first period and a decrease in the second period indepen- dent of peptide or placebo treatment. No signifcant $\mathrm{T} \times \mathrm{P}$ interactions were observed for the main and other variables (Table 2). One of the main vari- 
ables showed a significant $\mathrm{T} \times \mathrm{P} \times \mathrm{S}$ interaction $(F=6 \cdot 1 ; p<0.05)$, i.e. the total score of the verbal learning task. This was due to the changes in these parameters mentioned above. Thus, based on statistical analysis, no peptide effects were observed in this trial.

\section{Discussion}

A qualitative finding similar to one in trial 1 was the observation that several patients noted a feeling of improved performance and increased energy in the period of DGAVP treatment. Three of these patients were in the age-associated memory deficit group; one belonged to the mild brain trauma group. Interestingly, the fifth patient, who had had several psychotic episodes in the past and was now bothered by thinking and concentration difficulties, reported that he experienced increased mental activation in treatment period 1 (peptide), an effect which bothered him. This effect resembled the vasopressin effects noted in earlier studies with schizophrenic patients in which an increase in similar processes was found (e.g. Korsgaard et al., 1981).

\section{TRIAL 3}

An important change in trial 3 was the route of peptide administration. Although it was not clear whether the lack of effect was due to this variable, the change to intranasal application was judged to be necessary, especially in view of the increasing number of studies that report treatment effects of vasopressin peptides after intranasal application (e.g. in volunteers). A systematic comparison of the different routes of administration has not been performed, and there are few studies that have systematically examined the accessibility to the brain of peripherally administered peptides (but see Ang and Jenkins, 1982 and Riekkinen et al., 1987).

Another change was the introduction of a washout period between the two treatment periods. The rationale behind this change was the clinical impression that some subjects in trials 1 and 2 experienced an after-effect of DGAVP treatment in the first period, an effect which extended into the second treatment period. A third change was the group composition; because of the subjective improvements reported by particular patients with comparatively mild deficits in trials 1 and 2 , care was taken to increase the number of patients suffering from brain trauma and age-associated memory disorders. The hypothesis gradually emerged that these patients might be especially sensitive to DGAVP treatment.

\section{Materials and methods}

Subjects. Fourteen patients participated in this trial. All reported memory complaints of various severity; some also reported slowness in thinking, and concentration deficits. Table 1 shows the demographic and clinical data of the 10 males and four females. They had a mean age of $41 \cdot 1$ years with a range of 19-74 years. The group was heterogeneous with respect to the aetiology of the memory disorders: mild brain trauma $(n=3)$; moderate brain trauma $(n=3)$; senescent forgetfulness $(n=5)$; endocrine disorders $(n=2)$; encephalitis $(n=1)$. All patients met the inclusion and exclusion criteria described in trial 1 . The medical examination and neuropsychological investigation were as described in trial 1; the trial was approved by the Medical Ethical Committee. All patients were characterized by memory deficits without clear-cut disturbances in another cognitive domain. With respect to the nature of the memory dysfunction, 12 patients showed retrieval disturbances on neuropsychological examination, and nine patients also showed slight disturbances in consolidation of information into long-term memory. The speed of information processing into memory was disturbed in 11 patients, and two patients showed modalityspecific memory disorders.

Experimental design and procedure. All aspects of the design and procedure were similar to those described in trial 1, except for the introduction of a washout period, and the change in the route of administration of the drug (i.n.) and the dose $(1.0 \mathrm{mg})$. DGAVP was dissolved in water and administered with a nasal spray. The subject was instructed to puff in the air twice before administering one puff to each nostril once a day at 8 a.m. Compliance was tested by calculating the amount taken, as determined from the amount of fluid left in the flask after a 2-week treatment period. All subjects appeared to have taken the necessary amount. The second procedural change was the introduction of a washout period of 4 weeks between treatment periods 1 and 2, during which time there was no testing. The patients were tested before the start of the second treatment period. Thus, patients were tested seven times in this trial.

Data analysis. See trial 1. 
Tasks. See trial 1. A third task was introduced for treatment evaluation, namely the Stroop Colour Word Interference Task (see Lezak, 1983). This task consists of subtasks which measure, first, the speed at which colour names are read; second, the speed at which colours are named; third, the speed at which the colour of the printing ink is named when there is interference from the printed colour name. An interference score is calculated by subtracting the time scores for subtasks 3 and 2. The resulting four scores were taken as extra variables in treatment evaluation, thereby increasing the number of variables to 24 . The main variable was the interference score, which measures the speed of interference.

\section{Results}

The data of one patient were not complete; thus data from 13 patients were used for statistical analysis. The analysis of possible carry-over effect ( $t$-test) indicated a statistical significant effect for one of the eight main variables $(t=2 \cdot 8, p<0.05)$. This variable, the interference of the Stroop Colour Word Test, showed a decrease during the first but not the second treatment period, independent of placebo or peptide treatment, probably due to repeated testing. No significant $\mathrm{T} \times \mathrm{P}$ interactions for the main and other variables were found. Of the main variables, the interference of the Stroop Colour Word Interference Task showed a significant $\mathrm{T} \times \mathrm{P} \times \mathrm{S}$ interaction $(F=6.6 ; p<0.05)$, due to the effect described above, as did the four letters of the Memory Comparison Task $(F=4 \cdot 7$; $p<0.05$ ), an effect which was mainly due to the fact that placebo had a different effect in the two sequence groups. There was a slight but not significant beneficial effect of DGAVP treatment on this parameter (see Table 2). Thus, no statistically significant peptide effects were observed in this trial. Again, however, there were three subjects in the group of patients with mild trauma who reported subjectively an improvement in the period of peptide treatment.

\section{Discussion}

A close inspection of the test results of individual patients in trials 1 to 3 revealed that-on a single case level-there was a correlation between the subjective feelings of patients and the test results. The results of this comparison will be published elsewhere. On the basis of these findings and a survey of the relevant literature (see Jolles, 1987), we hypothesized that DGAVP might exert its effects only in patients without detectable anatomical damage in the brain; in view of the findings of trials 1 to 3, 'brain trauma' and 'senescent forgetfulness' appeared to be the most relevant patient groups. With respect to the former group, especially those subjects characterized by relatively minor or absent neurological abnormalities but prominent cognitive and neurasthenic complaints would be the diagnostic group of choice. It was thus decided to plan two additional trials, 4 and 5 , in which the patient groups would be homogeneous with respect to diagnosis.

\section{TRIAL 4}

\section{Materials and methods}

Subjects. Fourteen patients with mild to moderate head injury, according to Russell (1971), were selected for the experiment. Patients with evidence of a skill fracture, alcoholism, a focal neurological deficit, and neuropsychiatric disorder were excluded from the study. The age level was restricted to 45 years in order to prevent the possible interaction between cognitive after-effects of the trauma and those related to ageing processes. In addition, care was taken that all subjects were in a stationary phase after the trauma. Table 1 shows the demographic and clinical data of the 10 males and four females. They had a mean age of $25 \cdot 1$ years, with a range of $16-44$ years. The group was homogeneous as to aetiology of the memory disorders; 12 mild trauma and two moderate trauma. All patients met the inclusion and exclusion criteria described in trial 1. The medical examination and neuropsychological investigation were as described in trial 1; the trial was approved by the Medical Ethical Committee. With respect to the nature of the cognitive and behavioural complaints and deficits, a meticulous interview preceded the neuropsychological investigation. Most patients reported complaints about general and motor slowness, slowness in rate and efficiency of thinking, problems in coping with daily life, loss of energy, tiredness, decreased initiative, lowered concentration and memory complaints, especially when new information had to be processed. Some patients also reported autonomic complaints, such as dysregulation of body temperature, fatigue, etc. All patients were characterized by memory deficits without clear-cut disturbances in another cognitive 
domain. With respect to the nature of the memory dysfunction, the neuropsychological examination revealed retrieval disturbances in all patients. Four patients showed disturbances in the consolidation of information into long-term memory. All patients also showed disturbances in the organization of memory, and seven showed a decreased speed of information processing. One patient showed modality-specific memory disorders. The neuropsychological interpretations were based upon comparison of patients' test scores to norms obtained with various patient groups and healthy volunteers.

Experimental design and procedure. All aspects of the design and procedure were the same as in trial 3 except for the following small changes. The pretest at minus 2 weeks was discarded, as was the placebo pre-treatment of 2 weeks. There were two new pre-tests, namely at minus 8 and minus 4 weeks, in order to reduce the contribution of procedural learning to the criterion scores. The measurements in the middle of the treatment periods were also discarded. Thus, the patients were tested before and after the 4 weeks of treatment, and received two pre-tests. There was a washout period of 4 weeks between the treatment periods.

Tasks and data analysis.As done in trial 3.

\section{Results}

Since the aim of the trial was to study the effect of DGAVP in patients with mild brain trauma, the statistical analysis was performed on the 12 patients belonging to this category. As in trial 3, of the main variables only the interference score of the Stroop Colour Word Test showed a significant effect for possible carry over effects $(t=3 \cdot 1 ; p<0.05)$. This was again due to a decrease in the score during the first but not the second period of testing. This also led to a significant $\mathrm{T} \times \mathrm{P} \times \mathrm{S}$ interaction for this variable $(F=6.1 ; p<0.05)$. No other $\mathrm{T} \times \mathrm{P} \times \mathrm{S}$ interactions were observed. Two of the eight main variables showed $\mathrm{T} \times \mathrm{P}$ interactions, i.e. the total score of the Verbal Learning Task $(F=8.1 ; p<0.05)$ and the intercept of the Memory Comparison Task $(F=5.5 ; p<0.05)$. The total score of the Verbal Learning Task was increased after DGAVP treatment (Table 2). The same was found for the scores of the fifth presentation ( $T$ $\times \mathrm{P}$ interaction; $F=8.1 ; p<0.05$ ). This may indicate an improved learning performance after peptide treatment. The intercept of the Memory
Comparison Task was decreased after peptide treatment (Table 2), indicating an increased speed of information processing (Sternberg, 1975). Qualitatively, feelings of improvement were reported by almost all the patients as compared to three to four in the first three trials.

\section{Discussion}

It is of relevance to note that all patients in trial 4 can be regarded as suffering from the post-traumatic syndrome (Van Zomeren and Van den Burg, 1985), which is characterized by cognitive complaints in the realm of concentration, vigilance, sustained attention, inability to be involved with more than one task at a time, lack of energy and initiative, and autonomous dysregulation symptoms. The characteristics of the patients treated in trial 4 were consistent with this description. Thus, the results of this experiment add support to the hypothesis that DGAVP might be of particular use in the treatment of patients with symptoms associated with the post-traumatic syndrome or residual effects after mild brain trauma.

\section{TRIAL 5}

\section{Materials and methods}

Subjects. Twelve patients participated in this experiment. The minimum age for inclusion was 45 years. Those subjects were included in the experiment, who ascribed their memory complaints to their age and who experienced decreased memory function compared to periods earlier in their life. In addition, objective assessment of memory dysfunctions was essential to be included in the trial. All patients were characterized by a score of $3-4$ on the Global Deterioration Scale (Reisberg, 1983); by definition, two patients received the diagnosis dementia of the Alzheimer type, based upon the DSM III-R (American Psychiatric Association. 1987) and the NINCDS-ARDRA criteria (McKhann et al., 1984). The 10 other patients were not demented according to these criteria, but they fulfilled all or most of the criteria for AgeAssociated Memory Impairment as proposed by Crook et al. (1986). All patients met the inclusion and exclusion criteria described in trial 1. Table 1 shows the demographic and clinical data for the 11 males and one female. They had a mean age of $57 \cdot 1$ years, with a range of 48-68 years. The medical examination and neuropsychological investigation were as described in trial 1; the trial 
was approved by the Medical Ethical Committee. The neuropsychological examination revealed disturbances in retrieval from long-term memory, but also disturbances in memory organization, especially if interfering stimuli were present. Three patients showed disturbances in consolidation into long-term memory. Two patients showed modalityspecific memory disturbances.

\section{Experimental design and procedure. See trial 4.}

Tasks and data analysis. See trial 4.

\section{Results and discussion}

None of the main variables showed a significant effect when possible carry-over effects were tested. One of the main variables showed a significant $T$ $\times \mathrm{P}$ interaction, i.e. the four-letter test of the Memory Comparison Task $(F=5.3 ; p<0.05)$. In addition, this variable showed a significant $\mathrm{T}$ $\times \mathrm{P} \times \mathrm{S}$ interaction $(F=10.9 ; p<0.01)$, because of an increased score during placebo treatment in the first period. This may also underlie the significant $\mathrm{T} \times \mathrm{P} \times \mathrm{S}$ interaction on the calculated slope of this task $(F=6.0 ; p<0.05)$. A nearly significant peptide effect was observed for this slope $(F=4 \cdot 1$; $p<0 \cdot 1$ ). The data (Table 2) indicate that DGAVP treatment increased the speed of memory search in these patients (four-letter test, slope). Of the other variables only the total number of double words of the Verbal Learning Task showed a significant $\mathrm{T} \times \mathrm{P}$ interaction $(F=5.6 ; p<0.05)$. The number of double words increased after peptide treatment, as compared to placebo treatment. Furthermore, it is of relevance that none of the subjects in this group reported a feeling of improvement. This is in contrast to the patients with brain trauma and the older subjects in former trials.

\section{POST HOC ANALYSIS}

The results of trials 1-5 suggest that DGAVP affects cognitive performance in patients with brain trauma. There were significant effects in trial 4 (brain trauma patients), and qualitative findings but not statistically significant effects in the other trials. In addition, there were indications that the beneficial effects might be more clear-cut in patients with mild brain trauma rather than moderate brain trauma. Additional information on the patient group that responded optimally to drug treatment might be provided by post hoc analysis of the com- bined data from trials $1-5$. Important questions to be resolved by a post hoc analysis were whether the DGAVP effect found for patients with brain trauma in trial 4 was due to an effect specifically on patients with mild trauma, and whether this effect could also be found in similar patients from trials 1 to 3 . Another question referred to the DGAVP effect in older subjects. The slight effect of DGAVP in trials $1-4$ might be because of the small number of these subjects. If such an effect were present, it should be evident in post hoc analysis of the data of a larger number of patients. To answer these questions a post hoc analysis was performed on data from the following four groups: light brain trauma, moderate brain trauma, ageassociated memory deficits and dementia, and a miscellaneous group. The post hoc analysis was based on the premise that the contribution of the parameter 'diagnosis, or aetiology' was more important than the parameters 'treatment schedule', 'route of administration' and 'dose' that were varied from trial 1 to 5 . The treatment periods and treatment schedules were more or less identical for all parameters except those mentioned. In addition, because a washout period was included in trials, 3,4 and 5, it is unlikely that this parameter 'washout period' would influence the post hoc analysis, except in a conservative way. A final premise was that, for a thorough and relevant analysis, it was important that the diagnostic groups were not too unevenly distributed over both treatment groups (i.e. drug-placebo and placebo-drug). This was not the case.

\section{Materials and methods}

Subjects. The 68 patients were assigned to four groups according to diagnosis. Patients were included into the mild and moderate trauma groups according to the criteria mentioned in trial 1. Patients were assigned to the group AAMI/ dementia when their age was above 45 years and the deficits could not be ascribed to any factor other than age or early dementia. The criteria described by Crook et al. (1986) were used. Elderly subjects with endocrine deficits were thus assigned to the miscellaneous group.

Statistical analysis. Two post hoc analyses were performed. These analyses were directed at difference scores for all variables. The scores obtained before and after placebo treatment were subtracted. The same was done for the scores before and after 
DGAVP treatment. A paired $t$-test tested whether the difference scores were statistically similar or different. The subjects belonging to the treatment group DGAVP-placebo in trials 1 and 2 were discarded because of the lack of a washout period and the lack of a measure before the start of the placebo treatment. A first statistical analysis was directed at a comparison of the four patient groups; a second analysis addressed the question whether DGAVP affected patients with light versus moderate trauma differently.

\section{Results and discussion}

With respect to the first statistical analysis, the data of 53 patients were analysed: light brain trauma, $n=18$; moderate brain trauma, $n=10$; ageassociated memory deficits, $n=16$; miscellaneous group $n=9$. Significant differences in favour of DGAVP were especially found in the light trauma group. The main variable total score on the Verbal Learning Task was significantly higher after DGAVP treatment in these patients $(t=2.4 ; p<$ $0.05)$. The same was found for the second and the fourth trial of this test $(t=2.3 ; p<0.05$ and 2.6; $p<0.05$, respectively). In addition, there was a nearly significant effect of peptide treatment on the first trial $(t=1.9 ; p<0.1)$. This indicates that learning performance and memory retrieval in patients with light brain trauma are favourably influenced by the peptide. There was one statistically significant effect in the age-related memory deficit group (increased number of errors after DGAVP in the Memory Comparison Task ( $t=$ $2.6 ; p<0.05)$ ) and two in the miscellaneous group (a decreased performance after DGAVP in trial 4 of the Word Learning Test, $t=2.5 ; p<0.05$ and an increased number of false negatives in this test, $t=2 \cdot 3 ; p=0.05)$. The relevance of these data is not clear because of the small number of effects in relation to the number of comparisons made. With respect to the analysis of the differences between DGAVP effect in patients with light versus moderate brain trauma differences were found in the total score of the Word Learning Task ( $t=$ $2.6 ; p<0.05)$, and in the scores of trial $1(t=$ $2.0 ; p=0.05)$, trial $2(t=2.5 ; p<0.05)$, trial $4(t=2.0 ; p=0.06)$ and trial $5(t=2.4 ; p<$ 0.05 ) of this test. The data (Figure 1A,B) indicate that the performance of the patients with light brain trauma was improved by DGAVP, and that this effect was not present in the patients with moderate brain trauma. Taken together, the results from the post hoc analysis provide some supportive evidence for the findings of trials $1-5$. These results give rise to the notion that DGAVP has an effect on the performance of a particular group of patients, namely patients with mild brain trauma. This suggestion must be tested prospectively because of the relatively small number of effects in relation to the number of comparisons made.

\section{GENERAL DISCUSSION}

This paper describes a series of five consecutive clinical trials in which the effect of DGAVP was tested against placebo. The patient groups were selected according to defined inclusion and exclusion criteria. The presence of objective memory deficits without clear-cut dysfunctions in other cognitive domains was a prerequisite. Several experimental parameters were varied from trial to trial in order to find optimal conditions for the possible expression of a peptide effect. The major relevant factor in this respect appeared to be the factor 'diagnostic group', because statistically significant peptide effects were found in patients with light brain trauma. The systematic change of procedural parameters and diagnostic groups from trial to trial appears to have been of importance. Without a close look at the (non-significant) findings in the first three trials it would not have been possible to predict or hypothesize about the group of subjects that would benefit most from peptide treatment (i.e. the patients with light brain trauma). With respect to the variables 'route of administration' and 'dose', it has not been established in the present series of trials whether the intranasal route is superior to the oral route. This is because the variable 'diagnostic group' seemed to be of more importance. The presence of some patients who subjectively reacted to peptide treatment in the first two trials is an indication that oral treatment might be effective. Research directed at a comparison of several routes of administration should thus be performed.

The dose of $1 \mathrm{mg}$ DGAVP was probably not too high (see Jolles, 1987). One advantage of DGAVP above DDAVP, and especially LVP, is its relative lack of peripheral effects, which allows the use of higher dosages. Besides, doses up to $10 \mathrm{mg}$ of vasopressin peptides have been used successfully in studies with volunteers. It is therefore recommended that dose-response studies should be done with patients and that doses higher than $1.0 \mathrm{mg}$ should be used. It is probable that drug administration 

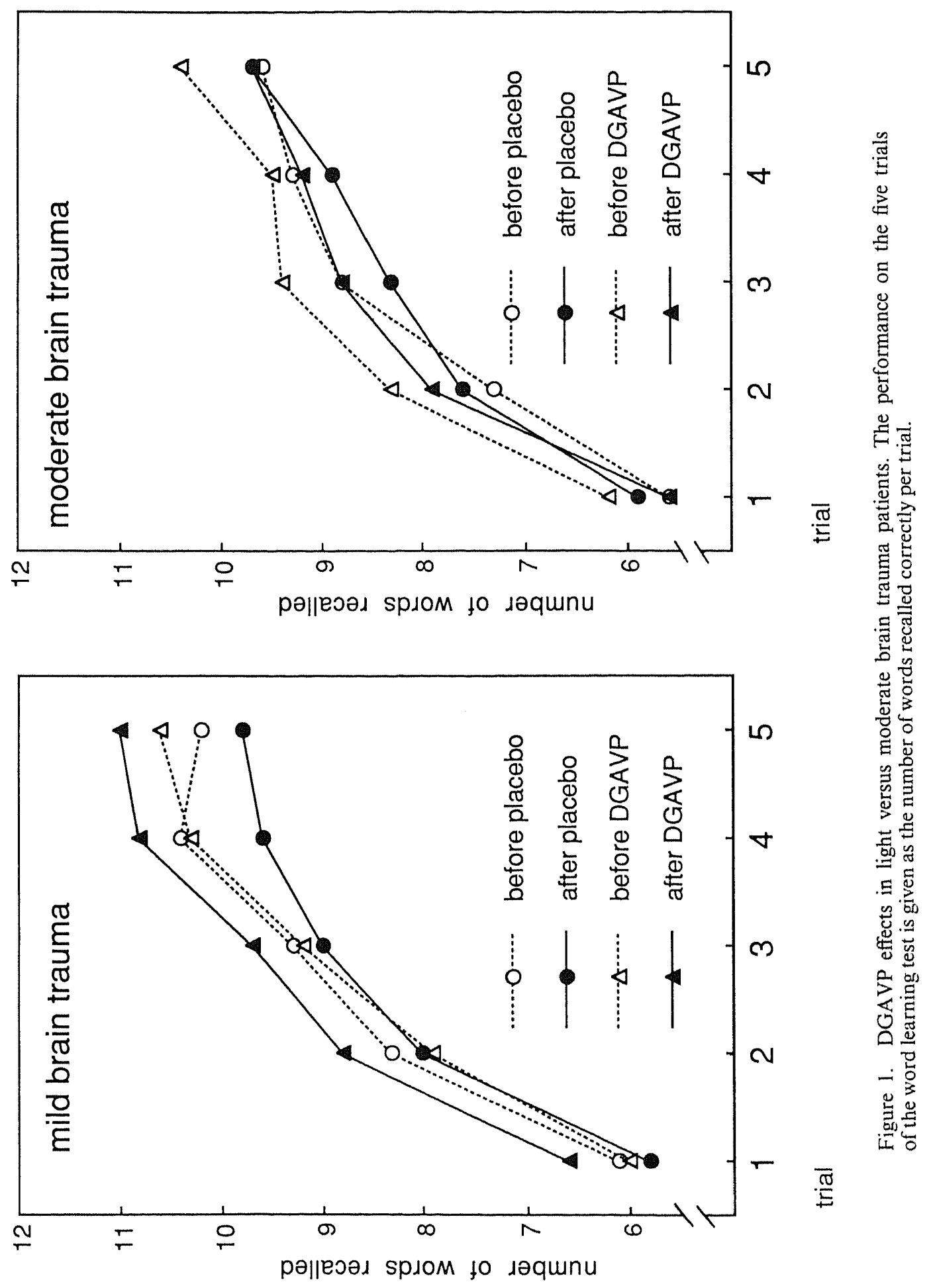
two or three times a day might be superior to once a day. This may allow a sufficient quantity of the peptide to be present in the brain during the hours that the subject is supposed to be active during the day. A 1-month period of treatment seems appropriate. There are several indications that 1 week is too short for a treatment effect to develop. For instance, Peabody et al. (1985) found evidence for a peptide effect in alcoholic patients, whereas Tinklenberg et al. (1982) found no such improvement in these patients in a study in which the treatment duration was shorter. In addition, TimsitBerthier et al. (1980) concluded that the peptide effects developed with time, which indicates that the treatment period should preferably be longer than a few weeks. Another important procedural variation in the present series of trials was the inclusion of a washout period in trial 3 . There is a qualitative impression that some subjects experienced an 'after-effect' of the DGAVP treatment in the first period, which extended over the second period. Interestingly, this effect of DGAVP resembles that made with vasopressin peptides in animal experiments, in which the behavioural effect of the peptide could still be found several days after administration. Thus, a comparison design seems best for future studies with vasopressin.

The finding that patients with brain trauma, especially the 'mild' cases, were affected by the peptide deserves closer attention. It is interesting to note that vasopressin peptides have been found to have effects in patients with mild to moderate brain trauma (e.g. Oliveros et al., 1978; Timsit-Berthier et al., 1980; Láczi et al., 1982, 1983a,b), but not in patients with severe brain trauma (e.g. Jenkins et al., 1981, 1982; Fewtrell et al., 1982). The therapeutic efficacy may thus depend on the extent to which structural lesions exist in the brain. The present trials, however, cannot be conclusive as to the effects on middle-aged or senile subjects, as there were too few of these subjects in trial 5 and in the post hoc analysis to allow definite conclusions to be drawn, especially because an effect on memory search was observed in these subjects (trial 5).

With respect to the significance of the findings done in the present series of clinical trials, it should be emphasized that the effects are small. The findings must therefore be regarded with some caution when interpreting their potential clinical significance. In addition, the statistical significance obtained in group comparison studies does not necessarily equate with therapeutic significance in individual patients. It could be the case that the groups contain individuals who improve more than others (for instance, the very mild brain trauma patients) and that the peptide effect is confined to such a subgroup. Prospective research should be performed in order to get more information on the possible clinical significance of the statistically significant findings presented here.

The nature of the vasopressin effect in humans is still disputed. In animal research it has been agreed that vasopressin and its congeners improve performance in tests in which aspects of memory processes are measured (Gash and Thomas, 1984; De Wied, 1984; Gash et al., 1987). However, there is disagreement as to the nature of this effect. De Wied and co-workers interpret the findings in terms of a specific effect on 'memory processes', whereas Gash and co-workers favour a 'general activating effect'. All recent experiments with DDAVP and DGAVP in human volunteers add support to the notion of a fairly specific effect on particular cognitive processes and not on others (see Jolles, 1986, 1987). However, as has been pointed out earlier (Jolles, 1987), comparisons are difficult because different authors interpret their findings according to various theoretical models and use different methods that do not measure identical cognitive processes. For instance, the vasopressin effects in humans have been described in terms of "more efficient organization and encoding of memory' (Weingartner et al., 1981a,b), 'facilitated attention' (Beckwith and Sandman, 1982; Beckwith et al., 1983) and improved 'concentration' (Legros and Lancranjan, 1984). Others find that VP especially improves parameters of speed, e.g. 'reaction time' (Durso et al., 1982) and 'tapping time' (Verhoeven et al., in Jolles, 1987). Several studies with volunteers are in favour of an effect on aspects of 'information processing', 'memory comparison time' and 'attentional processes' (e.g. Beckwith and Sandman, 1982; Beckwith et al., 1983, 1984; Nebes et al., 1984; Snel et al., 1987). Taken together, the results of the different studies might be indicative of a similar effect: there might be an increase in the rate of information processing, which can manifest itself in an increased efficiency in the organization of memory, but also in a subjective feeling of increased energy and-possibly - better mood.

In summary, the research described in this paper shows that DGAVP has a small beneficial effect on the performance of patients with light brain trauma in the Verbal Learning Task. Future research should focus on patient groups which are still better described in terms of neuropsychological 
functioning. Procedural variables as well as the tasks are important. Knowledge about the precise mechanism of action and possible clinical application of this neuropeptide is dependent upon a precise control of procedural as well as patient characteristics. The findings reported in this paper suggest that clinical trials should be performed with a sufficient number of (very) mild head trauma patients. As well as DGAVP effects in post-traumatic syndrome, trials in which mild head injury patients are immediately treated after the trauma in order to accelerate the recovery process are of interest. Trials with age-related memory dysfunctions are also of potential interest in the light of the present findings; care should be taken to include only mild, or mild to moderate patients.

\section{ACKNOWLEDGEMENTS}

The authors wish to thank Dr F. J. van der Staay for his important contribution to the statistical analyses. Part of the research was performed under grant 900-052-034 from Medigon, Science Council of the Netherlands (NWO).

\section{REFERENCES}

American Psychiatric Association (1987). Diagnostic and Statistical Manual of Mental Disorders, 3rd edn, revised. Author, Washington, DC. Mood disorders, pp. 23-233.

Ang, V. T. Y. and Jenkins, J. S. (1982). Blood CSF barrier to arginine-vasopressin, desmopressin and desglycinamide arginine-vasopressin in the dog. Journal of Endocrinology, 93, 319-325.

Beckwith, B. E. and Sandman, C. A. (1982). Central nervous system and peripheral effects of ACTH, MSH and related neuropeptides. Peptides, 3, 411-420.

Beckwith, B. E., Couk, D. I. and Till, T. S. (1983). Vasopressin analog influences the performance of males. Peptides, 4, 707-709.

Beckwith, B. E., Til, R. E. and Schneider, V. (1984). Vasopressin analog (DDAVP) improves memory in human males. Peptides, 5, 819-822.

Brand, N. and Jolles, J. (1985). Learning and retrieval rate of words presented auditorily and visually. Journal of General Psychology, 112, 201-210.

Brand, N. and Jolles, J. (1987). Information processing in depression and anxiety. Psychological Medicine, 17,145-154.

Christensen, A. L. (1975). Luria's Neuropsychological Investigation. Munxgaard, Copenhagen.

Crook, T., Bartus, R. T., Ferris, S. H., Whitehouse, P., Cohen, G. D. and Gershon, S. (1986). Age-associated memory impairment: proposed diagnostic criteria and measures of clinical change. Report of a National
Institute of Mental Health Work Group. Developmental Neuropsychology, 2, 261-276.

Deelman, B. G., Brouwer, W. H., Van Zomeren, A. H. and Saan R. J. (1980). Functiestoornissen na trauma capitis. In: Neuropsychology in Nederland, JennekensSchinkel, A., Diamant, J. J., Diesfeldt, H. F. A. and Haaxma, R. (eds). Van Loghum Slaterus, Deventer, pp. 251-281.

De Wied, D. (1969). Effects of peptide hormones on behavior. In: Frontiers in Neuroendocrinology, Ganong, W. F. and Martini, L. (eds). Oxford University Press, London, pp. 97-140.

De Wied, D. (1984). The importance of vasopressin in memory. Trends in Neuroscience, 7, 62-63.

De Wied, D. and Jolles, J. (1983). Neuropeptides derived from pro-opio-melanocortin: behavioral, physiological and neurochemical effects, Physiology Review, 62 , 976-1059.

Durso, R., Fedio, P., Brouwers, P. et al. (1982). Lysine vasopressin in Alzheimer's disease. Neurology, 32, 674-677.

Fewtrell, W. D., House, A. O. Jamie, P. F., Oates, M. R. and Cooper, J. E. (1982). Effects of vasopressin on memory and new learning in brain-injured population. Psychological Medicine, 12, 423-425.

Fraenkel, H. M., Van Beek-Verbeek, G., Fabriek, A. J. and Van Ree, J. M. (1983). Desglycinamide"-arginine"vasopressin and ambulant methadone-detoxification of heroin addicts. Alcohol and Alcoholism, 18, 331-335.

Gash, D. M. and Thomas, G. T. (1984). The importance of vasopressin in memory: Reply, Trends in Neuroscience, 7, 64-65.

Gash, D. M., Herman, J. P. and Thomas, G. J. (1987). Vasopressin and animal behavior. In: Vasopressin Principles and Properties, Gash, D. M. and Boer, G. J. (eds). Plenum Press, New York, pp. 517-547.

Houx, P. J., Vreeling, F. W. and Jolles, J. (1991a). Ageassociated cognitive decline is related to biological life events. In: Alzheimer's Disease: Basic Mechanisms, Diagnosis and Therapeutic Strategies (Iqbal, K., McLachlin, D. R. C., Winblad, B. and Wisniewski, H. M. (eds). John Wiley, Chichester, pp. 353-358.

Houx, P. J., Vreeling, F. W. and Jolles, J. (1991 b). Rigorous health screening reduces age effect on Memory Scanning Task. Brain and Cognition, 15, 246 260.

Jenkins, J. S., Mather, H. M., Coughlan, A. K. and Jenkins, D. G. (1981). Desmopressin and desglycinamide vasopressin in posttraumatic amnesia, Lancet, 1, 39 .

Jenkins, J. S., Mather, H. M. and Coughlan, A. K. (1982). Effects of desmopressin in normal and impaired memory. Journal of Neurology, Neurosurgery and Psychiatry, 45, 830-831.

Jolles, J. (1983). Vasopressin-like peptides and the treatment of memory disorders in man. In: The Neurohypophysis: Structure, Function and Control, Cross, B. A. and Leng, G. (eds). Elsevier, Amsterdam, pp. 169-182.

Jolles, J. (1985). Early diagnosis of dementia: possible contributions from neuropsychology. In: Senile 
Dementia of the Alzheimer Type, Traber, J. and Gispen, W. H. (eds). Springer Verlag, Berlin, pp. 84-100.

Jolles, J. (1986). Neuropeptides and cognitive disorders. In: Psychiatric Disorders: Neurotransmitters and Neuropeptides, Van Ree, J. M. and Matthijse, J. (eds). Elsevier, Amsterdam, pp. 177-192.

Jolles, J. (1987). Vasopressin and human behavior. In: Vasopressin Principles and Properties, Gash, D. M. and Boer, G.J. (eds). Plenum Press, New York, pp. 549578.

Korsgaard, S., Casey, D. E., Damgaard Pedersen, N. E., Jörgensen, A. and Gerlach, J. (1981). Vasopressin in anergic schizophrenia. Psychopharmacology, 74, 379 382.

Láczi, F., Valkusz, Zs., Laszlo, F. A. et al. (1982). Effects of lysine-vasopressin and 1-desamino-8-D-argininevasopressin on the memory of healthy individuals and diabetes insipidus patients. Psychoneuroendocrinology, 7, 195-193.

Láczi, F., Van Ree, J. M., Wagner, A. et al. (1983a). Effects of desglycinamide-arginine-vasopressin (DGAVP) on memory processes in diabetes insipidus patients and in non-diabetic subjects. Acta Endocrinologica, 102, 205-212.

Láczi, F., Van Ree, J. M., Balogh, L. et al. (1983b). Lack of effect of dysglycinamide-arginine-vasopressin (DGAVP) on memory in patients with Korsakoff's syndrome. Acta Endocrinologica, 104, 177-182.

Le Boeuf, A., Lodge, J. and Eames, P. G. (1978). Vasopressin and memory in Korsakoff syndrome. Lancet, 2,1370 .

Legros, J. J. and Lancranjan, I. (1984). Vasopressin in neuropsychiatric disorders. In: Psychoneuroendocrine Dysfunction, Shah, N. S. and Donald, A. G. (eds). Plenum Press, New York, pp. 255-278.

Legros, J. J., Gilot, P., Seron, X. et al. (1978). Influence of vasopressin on learning and memory. Lancet, 1 , $41-42$.

Lezak, M. D. (1983). Neuropsychological Assessment, 2nd edn. Oxford University Press, New York.

McKhann, G., Drachman, D., Folstein, M., Katzman, R., Price, D. and Stadlan, E. M. (1984). Clinical diagnosis of Alzheimer's disease. Report of the NINCSADRDA Work Group under the auspices of the Department of Health and Human Services Task Force on Alzheimer's disease. Neurology, New York, 34, 939-944.

Nebes, R. D., Reynolds, C. F. III and Horn, L. C. (1984). The effect of vasopressin on memory in the healthy elderly. Psychiatry Research, 11, 49-59.

Oliveros, J. C., Jandali, M. K., Timsit-Berthier, M., Remy, R., Benghezal, A., Audibert, A. and Moeglen, J. M. (1978). Vasopressin in amnesia. Lancet, 1, 42.

Peabody, C. A., Thiermann, S., Pigache, R., Miller, T. P., Berger, Ph. A., Yesavage, J. and Tinklenberg, J. R. (1985). Desglycinamide-9-Arginine-8-Vasopres$\sin$ (DGAVP, Organon 5667) in patients with dementia. Neurobiology of Aging, 6, 95-100.
Riekkinen, P., Legros, J. J., Sennef, C., Julkkonen, J., Smitz, S. and Soininen, H. (1987). Penetration of DGAVP (org 5667) across the blood-brain barrier in human subjects. Peptides, 8, 261-265.

Reisberg, B. (1983). Clinical presentation, diagnosis and symptomatology of age-associated cognitive decline and Alzheimer's disease. In: Alzheimer's Disease, Reisberg, B. (ed.). Free Press, New York, pp. 173-183.

Rey, A. (1964). L'examen psychologique dans les cas d'encephalopathie traumatique. Presses Universitaires de France, Paris.

Russell, E. W. C. (1971). The Traumatic Amnesias. Oxford University Press, Oxford.

Russell, E. W. C. (1981). The pathology and clinical examination of memory. In: Handbook of Clinical Neuropsychology, Filskov, S. B. and Boll, T. J. (eds). John Wiley, New York, pp. 287-319.

Snel, J., Taylor, J. and Wegman, H. (1987). Does DGAVP influence memory, attention and mood in young healthy men? Psychopharmacology, 92, 224 228.

Squire, L. R. and Davis, H. P. (1981). The pharmacology of memory: a neurobiological perspective. Annual Review of Pharmacology and Toxicology, 21, 323-356.

Sternberg, S. (1975). Memory scanning; new findings and current controversies. Quarterly Journal of Experimental Psychology, 27, 1-32.

Timsit-Berthier, M., Mantanus, H., Jacques, M. C. and Legros, J. J. (1980). Utilité de la lysine-vasopressine dans le traitement de l'amnésia post-traumatique. Acta Psychiatrica Belgica, 80, 728-747.

Tinklenberg, J. R., Pigache, R., Pfefferbaum, A. and Berger, P. A. (1982). Vasopressin peptides and dementi. In: Alzheimer's Disease, A report of Progress in Research, Corkin, S., Davis, K. I., Growdon, J. H., Usdin, E. and Wurtman, R. J. (eds). Raven Press, New York, pp. 463-469.

Van Beek-Verbeek, G., Fraenkel, H. M. and Van Ree, J. M. (1983). Desgly ${ }^{9}-\left[\mathrm{Arg}^{8}\right]$-Vasopressin may facilitate methadone detoxification of heroin addicts. Substance, Alcohol Actions/Misuse, 4, 375-382.

Van Ree, J. M., Hijman, R., Jolles, J. and De Wied, D. (1985). Vasopressin and related peptides: Animal and human studies. Progress in Neuro-Psychopharmacology and Biological Psychiatry, 9, 551-559.

Van Ree, J. M., Jolles, J. and Verhoeven, W. M. A. (1990). Neuropeptides and Psychopathology. In: Neuropeptides: Basics and Perspectives, De Wied, D. (ed.). Elsevier, Amsterdam, pp. 313-351.

Van Wimmersma Greidanus, Tj. B., Bohus, B. and De Wied, D. (1976). CNS sites of action of ACTH, MSH and vasopressin in relation to avoidance behavior. In: Anatomical Neuroendocrinology, Strumpf, W. E. and Grant, L. D. (eds). Karger, Basel, pp. 284-289.

Van Zomeren, A. H. and Van den Burg, W. (1985). Resi- 
dual complaints of patients two years after severe head injury. Journal of Neurology, Neurosurgery and Psychiatry, 48, 21-28.

Vink, M. and Jolles, J. (1985). A new version of the Trail Making Test as an information processing task. Journal of Clinical and Experimental Neuropsychology, $7,162$.
Weingartner, H., Gold, P., Ballenger, J. C. (' al. (1981 a). Effects of vasopressin on human memory functions. Science, 211, 601-603.

Weingartner, H., Kaye, W., Gold, P., Smallberg, S.. Peterson, R., Gillin, J. C. and Ebert, M. (1981b). Vassopressin treatment of cognitive dysfunction in progressive dementia. Life Sciencess, 29, 2721 2726. 